\title{
IMPACT OF RCP4.5 CLIMATE CHANGE SCENARIO ON THE BIOCLIMATIC POTENTIAL OF SIX SELECTED EUROPEAN LOCATIONS
}

\author{
M. KOŠIR ${ }^{1}$, J. POTOČNIK ${ }^{2}$ \& L. PAJEK ${ }^{3}$ \\ Faculty of Civil and Geodetic Engineering, University of Ljubljana, Slovenia.
}

\begin{abstract}
As the evidence for anthropogenic climate change is mounting, the need to evaluate its potential impacts in upcoming decades is becoming ever more important. As urbanised environments will be substantially affected, the evaluation of climate change impacts on building performance is crucial to ensure the sustainability and resilience of the built environment. In order to evaluate a building's potential to adapt to the climatic conditions of its location, a bioclimatic analysis can be performed to determine and evaluate the potential for the application of bioclimatic design strategies (e.g. passive solar heating, shading, etc.). The presented paper reports on a bioclimatic analysis for the cities of Paris, Berlin, Ljubljana, Moscow, Rome and Madrid performed using the BcChart tool. Firstly, the bioclimatic potential in accordance with the 'current' climate state (i.e. 1980-2000 period) was determined. Secondly, the current climate data were morphed using WeatherShift ${ }^{\mathrm{TM}}$ application and IPCC's AR5 RCP4.5 climate change scenario. Then, the future bioclimatic potential was determined up to year 2100. In order to facilitate the scenario uncertainties, the analysis was conducted for the 10th and 90th percentile of mean daily temperature change. The results show that the projected climate change will result in a noticeable shift of bioclimatic potential in all of the analysed locations. Overall, for temperate and cold climates the period of thermal balance with the environment will increase, however under the presumption that effective overheating prevention (e.g. shading) is applied. A simple ecoeconomic analysis for Ljubljana showed that investment in automated shading is acceptable for the 30 -year period. On the other hand, for Mediterranean and hot semi-arid climates, the temperature rise will result in the increased portion of the year when overheating mitigation measures are needed.

Keywords: bioclimatic design, bioclimatic potential, climate change, eco-economic analysis, shading.
\end{abstract}

\section{INTRODUCTION}

The current as well as the predicted future climate change have and will have global implications for human civilisation as well as for the entire Earth biosphere. In the context of direct and indirect effects on human society and economy, the urbanised environments (i.e. cities) will be disproportionally affected compared to the rural environments due to higher vulnerability of cities in regards to the resilience to climatic changes [1]. The impact of cities and their exposure to the negative effects of climate change (e.g. impact on energy-systems, flooding, drought, overheating, etc.) [2] is even further emphasised by the fact that more than one half of global human population lives in cities, while at the same time $75 \%$ of $\mathrm{CO}_{2}$ emissions are the result of cities' energy use [3]. Furthermore, the increase of urbanisation is not expected to decline in the current century, meaning that ever-larger populations will live in cities. It is projected that by 2050 the number of potentially affected urban dwellers will increase by 2 billion [1]. The projected added urban dwellers will be primarily in the developing countries, living in informal settlements with high risks to extreme weather phenomena [4]. While the main risks for cities in the developing and the developed world might differ, the importance of climate change mitigation and adaptation is crucial for all because the two

1 http://orcid.org/0000-0001-5030-7404

2 http://orcid.org/0000-0002-6455-7145

3 http://orcid.org/0000-0002-7758-2104 
are complementary strategies for responding to climate change [2]. In the case of the developed countries, the impact of buildings on the mitigation of climate change effects is crucial due to their large operational energy consumption and consequential high $\mathrm{CO}_{2}$ emissions, providing a significant feedback loop that drives further climate change.

The described situation and a large potential of buildings for achieving the goals of Paris climate agreement through increased energy efficiency [5] as well as overall environmental impact [6] was recognized by EU policy makers. However, such measures, primarily focused on mitigation and not adaptation, are according to the Intergovernmental Panel on Climate Change (IPCC) fifth assessment (AR5) climate change report [2] insufficient in order to appropriately prepare buildings and cities for the full spectrum of climate change related impacts. In regards to the adaptation of buildings to climate change, the importance of occupant indoor thermal comfort is crucial, as numerous studies emphasize that occupant behaviour can substantially influence the thermal performance of buildings [3]. In the context of climate change, if appropriate adaptation measures on the level of design, retrofit and operation of buildings are not implemented, this can result in increased energy use for cooling due to higher average ambient temperatures. Primarily, this means that in current heating driven locations (e.g. Central Europe) in the near future cooling energy use might substantially increase [7-9], if no passive bioclimatic adaptation strategies [10] are implemented in the design of new and retrofit of current buildings. These design strategies (e.g. efficient shading, cross ventilation, night-time ventilation, high thermal mass, etc. [11]) would enable building occupants to achieve appropriate levels (i.e. equal or higher than at present) of indoor comfort with minimum or no additional energy use. Such pre-emptive adaptation is extremely important in the case of building design, because buildings and urban environments in general have a substantial lock-in risk due to long lifespans of buildings and their components. This means that a building constructed today will not be substantially modified in the next 30+ years. Therefore, its future energy efficiency might decrease, as it was shown by Pajek and Košir [9] on a case of residential bioclimatic building optimised for current Central European climate of Slovenia. As a result, building design strategies have to be in step with climate change, which means that passive building design features, which may bring crucial adaptation benefits in the future, have to be considered today.

The presented paper deals with the identification of future climate change induced shifts in bioclimatic potential of six European cities (i.e. Paris, Berlin, Ljubljana, Moscow, Rome and Madrid) up to the end of the 21st century, representing the main climatic types of continental Europe. The calculations were performed using the BcChart software developed by Košir and Pajek [12], based on the bioclimatic chart theory developed by Olgyay [10]. The focus of the analysis was on the identification of shifts in achieving indoor comfort by passive means only in relation to the IPCC's Representative Concentration Pathways 4.5 (RCP4.5) climate change scenario. In other words, the bioclimatic design strategies that should be implemented in the buildings, which will better adapt to the future climate, were identified. In the end, a simple eco-economic evaluation of shading implementation in case of two residential buildings situated in Ljubljana, Slovenia was conducted.

\section{METHODOLOGY}

For the purpose of this paper, the bioclimatic potential of six climatologically different European locations was determined by BcChart tool. This was done for the present climate and additionally for the future, namely until the end of the 21 st century. The calculation of future state was performed using RCP4.5 climate change scenario for the 10th and the 90th percentile. In the end, a simple eco-economic assessment of shading application was made. 


\subsection{Bioclimatic potential}

Bioclimatic potential analysis of a location (its climate) is very useful in order to facilitate the design of climate responsive buildings that assure sufficient thermal comfort and efficient energy use. Such analysis can be used in order to define passive building design strategies, which satisfy climate adaptability, sustainability and to some degree also resilience of buildings. For example, in temperate and cold climate, the prevailing strategies of passive building design are mostly focused on providing thermal comfort, when outdoor temperatures are low. This can be assured by harvesting solar energy, compact building shape, low thermal transmittance, etc. In contrast, in hot or Mediterranean climate the location's bioclimatic potential for building design can be utilised by shading, high thermal mass, natural ventilation, etc.

For the calculation of bioclimatic potential at selected locations, we used the BcChart [12] software developed at the University of Ljubljana, Slovenia. The software delivers bioclimatic potential analysis of a location based on the theory of Olgyay's bioclimatic chart [10]. The bioclimatic potential is calculated by using climate data, such as air temperature, relative humidity and solar irradiance, which define if thermal comfort inside a building at that location could be 'naturally' achieved or not; and if not, which passive building design strategies would be beneficial for achieving it. Accordingly, the bioclimatic potential calculated by BcChart is expressed in percentages, calculated either on yearly or monthly level, when any of the aforementioned is possible. The detailed methodology used in BcChart is presented in the paper by Pajek and Košir [13]. For the purpose of the study we observed the results on the extent of the comfort zone $\left(\mathrm{C}_{\mathrm{z}}\right)$, which consists of $\mathrm{C}_{\mathrm{sn}}$ (i.e. comfort achieved by solar energy harvesting) and $\mathrm{C}_{\mathrm{sh}}$ (i.e. comfort achieved with shading). Additional observed parameters were the duration of the period when solar energy harvesting is desired, but the amount available may be insufficient $(\mathrm{R})$, the time of year when only conventional heating is possible $(\mathrm{H})$ and the time of year when passive measures for overheating prevention (i.e. natural ventilation, high thermal mass, evaporative cooling, etc.) are necessary $(\mathrm{V})$. If $\mathrm{V}$ and $\mathrm{C}_{\mathrm{sh}}$ values are summed up, this results in $\mathrm{Sh}$ value, namely the share of the year when shading is needed. Conversely, the sum of $\mathrm{C}_{\mathrm{sn}}, \mathrm{R}$ and $\mathrm{H}$ is the $\mathrm{Sn}$ value, namely the share of the year when solar energy harvesting is necessary.

\subsection{RCP climate change scenarios}

In order to simulate the climate situation of continental Europe up to the end of the 21st century, the IPCC's 'benchmark emission scenarios' referred to as Representative Concentration Pathways (RCPs) were used. The latest RCPs were issued based on the IPCC's AR5 report $[2,3]$. There are four RCPs that depend on the projected amount of global greenhouse gas (GHG) emissions, namely RCP2.6, RCP4.5, RCP6.0 and RCP8.5. Each of the scenarios is characterized by the projected amount of radiative forcing in $\mathrm{W} / \mathrm{m}^{2}$ as a consequence of multiple climate change factors. Radiative forcing is defined as the difference between the received solar energy and the emitted thermal radiation of the Earth. A positive value denominates that the Earth receives more energy than it reradiates back to the cosmos, so the climate system is consequently heating up [14].

RCP2.6 is a stringent mitigation pathway where radiative forcing peaks at approximately only $2.6 \mathrm{~W} / \mathrm{m}^{2}$ before 2100 and then decays [15]. Effectively, such scenario assumes that $\mathrm{CO}_{2}$ emissions would peak soon after 2020 and then they would substantially reduce until the end of 21 st century [14]. The 'intermediate' scenarios RCP4.5 and RCP6.0 are stabilization pathways in which radiative forcing is stabilized at approximately $4.5 \mathrm{~W} / \mathrm{m}^{2}$ and $6.0 \mathrm{~W} / \mathrm{m}^{2}$ after 2100 [15]. The RCP4.5 would reach peak $\mathrm{CO}_{2}$ emissions around 2050 and RCP6.5 around 
2080, with substantial reductions in emissions until mid-22nd century for both scenarios [14]. The RCP8.5 scenario represents a situation with very high GHG emission pathway, for which radiative forcing reaches $>8.5 \mathrm{~W} / \mathrm{m}^{2}$ by 2100 and continues to persist for some amount of time. In particular, pathways ranging between RCP6.0 and RCP8.5 are scenarios of a result without any effort to reduce the anthropogenic GHG emissions, called business as usual scenarios. On the other hand, RCP2.6 is a typical scenario that aims at keeping global warming likely below $2{ }^{\circ} \mathrm{C}$ above pre-industrial temperatures. RCP4.5 is an intermediate scenario and follows a cost-minimizing pathway [16]. Because the RCP4.5 scenario is probably the most realistic (and optimistic), it was used for the analyses made within this study. RCP4.5 aims at achieving stable radiative forcing until 2100. In RCP4.5 global surface temperature change until 2100 is projected to likely exceed $1.5^{\circ} \mathrm{C}$ (high confidence), but not to exceed $2^{\circ} \mathrm{C}$ (medium confidence), if compared to the pre-industrial temperatures [15]. However, we have to be aware that each of the RCPs provides only one of many possible scenarios that would lead to the specific radiative forcing characteristics up to 2100 .

\subsection{Analysed locations and climate data}

The bioclimatic potential was calculated at six different locations across Europe. The locations were chosen in order to represent typical European climate types, and they are dispersed over a wide area of Europe (Fig. 1 and Table 1).

In order to calculate the bioclimatic potential of the selected five locations with BcChart software, the acquisition of climate data, namely air temperature, relative humidity and solar irradiance, was necessary. This was done by acquiring relevant EnergyPlus weather files (EPW) [19] for the recent climate conditions at the selected five locations. Next, the selected EPW files were used to produce morphed EPW files adjusted according to the predicted future conditions as a result of changing climate. The morphing was conducted using the aforementioned IPCC's RCP4.5 climate scenario. The latter was done by using WeatherShift ${ }^{\mathrm{TM}}$ tool [20], which uses data from global climate change models to produce EPW files for the projected future state of the climate. The projected data were observed for three time periods (i.e. 2035, 2065 and 2090) up to the end of the 21 st century. To obtain the range of possible changes, we observed the 10th and 90th percentile values.

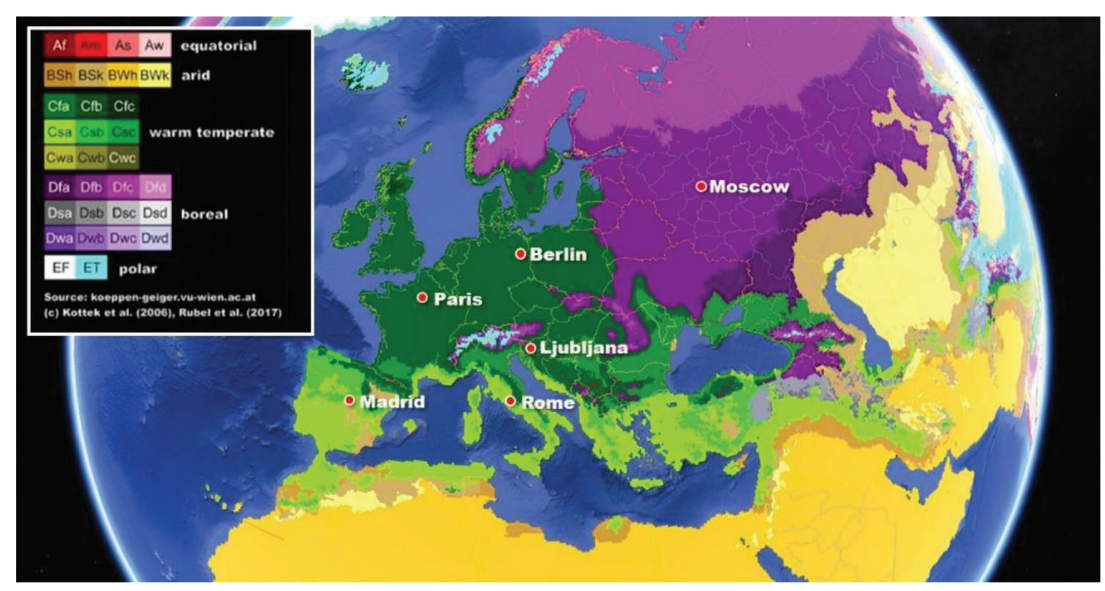

Figure 1: Analysed locations with respect to their geographic locations and Köppen-Geiger climate types (period 1986-2010 in resolution of 10 arc minutes) [17,18]. 
Table 1: The selected locations and their characteristics.

\begin{tabular}{lllllll}
\hline & \multicolumn{7}{c}{$\begin{array}{l}\text { Köppen-Geiger } \\
\text { climate classifi- } \\
\text { cation [17] }\end{array}$} & $T_{\text {min,avg }}\left[{ }^{\circ} \mathrm{C}\right]$ & $\begin{array}{l}T_{\text {max,avg }} \\
{\left[{ }^{\circ} \mathrm{C}\right]}\end{array}$ \\
\hline Moscow & $55.75^{\circ} \mathrm{N}$ & $37.63^{\circ} \mathrm{E}$ & 156 & $\mathrm{Dfb}$ & $-11.8(\mathrm{Feb})$ & $23.2(\mathrm{Jul})$ \\
Berlin & $52.47^{\circ} \mathrm{N}$ & $13.40^{\circ} \mathrm{E}$ & 49 & $\mathrm{Cfb}$ & $-2.0(\mathrm{Feb})$ & $23.4(\mathrm{Jul})$ \\
Paris & $48.73^{\circ} \mathrm{N}$ & $2.40^{\circ} \mathrm{E}$ & 96 & $\mathrm{Cfb}$ & $1.6(\mathrm{Feb})$ & $25.0(\mathrm{Aug})$ \\
Ljubljana & $46.37^{\circ} \mathrm{N}$ & $14.80^{\circ} \mathrm{E}$ & 385 & $\mathrm{Cfb}$ & $-4.9(\mathrm{Jan})$ & $26.4(\mathrm{Jul})$ \\
Rome & $41.80^{\circ} \mathrm{N}$ & $12.23^{\circ} \mathrm{E}$ & 3 & $\mathrm{Csa}$ & $4.7(\mathrm{Feb})$ & $28.7(\mathrm{Aug})$ \\
Madrid & $40.45^{\circ} \mathrm{N}$ & $3.55^{\circ} \mathrm{W}$ & 582 & $\mathrm{BSk}$ & $1.4(\mathrm{Jan})$ & $33.2(\mathrm{Jul})$ \\
\hline
\end{tabular}

\section{RESULTS AND DISCUSSION}

Previously conducted studies motivated us to investigate the impact of changing environment at different locations, because it is expected that global climate change will have substantially diverse regional implications. With respect to building performance, it could be said that climate change will affect the ratio between the period of year when building needs shading and the period when solar energy should be harvested in order to achieve thermal comfort. Table 2 represents the results obtained by BcChart analyses, where the trend of escalated Sh (i.e. shading is needed) and $\mathrm{C}_{\mathrm{sh}}$ (i.e. comfort achieved with shading) values and contrariwise reduction of $\mathrm{C}_{\mathrm{sn}}$ value (i.e. comfort achieved by solar energy harvesting) can be seen.

Table 2: Projected future trends of Sh, $\mathrm{C}_{\mathrm{sh}}$ and $\mathrm{C}_{\mathrm{sn}}$ for the six analysed locations. The difference $(\Delta)$ is calculated according to the current climate state.

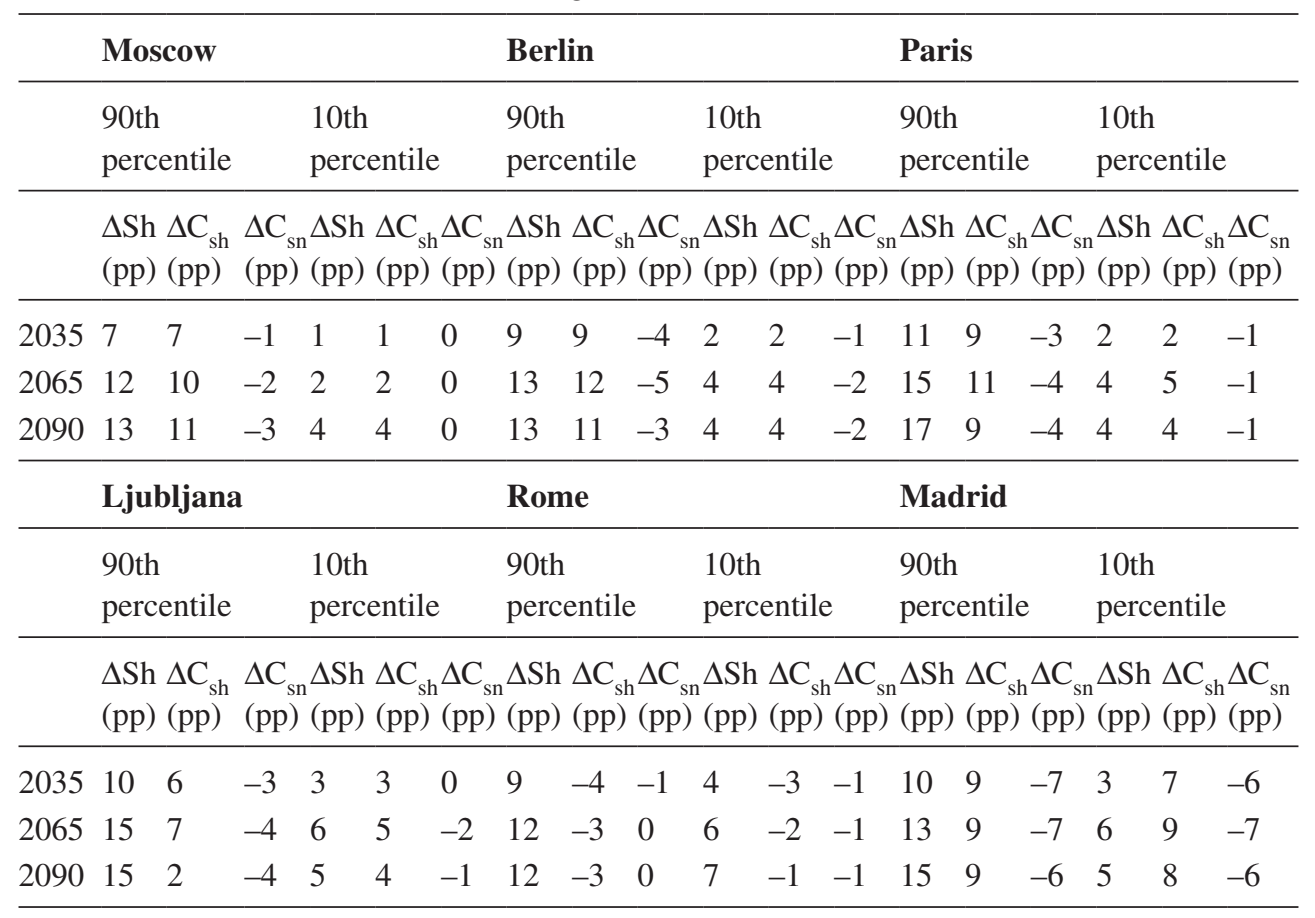


In all the analysed locations, Sh values rise in time emphasising the growing importance to incorporate shading devices into building design, but also into urban context (e.g. planting trees, street shading etc.). In most of the cases, the time when comfort zone is achieved will increase under the presumption that appropriate shading is provided, because the $\mathrm{C}_{\mathrm{sh}}$ values rise more significantly than the $\mathrm{C}_{\mathrm{sn}}$ decreases. However, the proportion between the increase in $\mathrm{C}_{\mathrm{sh}}$ and the decrease in $\mathrm{C}_{\mathrm{sn}}$ depends of the analysed location. The trends presented in Table 2 suggest the necessity of a more in depth analysis of the phenomenon. Therefore, the main results of the study are presented in the two following subsections, where in subsection 3.1 the projected trends of the time dependant range of achieved comfort are presented for different locations. In subsection 3.2, the projected changes in bioclimatic potential and their implications on the design strategies for buildings are discussed. Both discussed topics have substantial implications for the future design of buildings and are largely affected by projected climate change trends. In the end, subsection 3.3 discusses the ecological and economic implications of shading application for the location of Ljubljana.

\subsection{Projected trends of comfort zone $(\mathrm{Cz})$ change due to RCP4.5 climate change scenario}

Since $\mathrm{C}_{\mathrm{z}}$ value represents the combination of $\mathrm{C}_{\mathrm{sn}}$ and $\mathrm{C}_{\mathrm{sh}}$, it was expected that the percentage of time when $\mathrm{C}_{\mathrm{z}}$ is achieved will show an increasing trend until the end of the 21 st century. This was presumed as a consequence of increase in average temperatures during transitional months between summer and winter, which is especially visible in temperate and colder climates.

Trends of the projected $\mathrm{C}_{\mathrm{z}}$ range for the six chosen locations are shown in Fig. 2, where Berlin and Moscow clearly share the trend of rising $\mathrm{C}_{\mathrm{z}}$ value. This is a consequence of achieving thermal comfort by shading $\mathrm{C}_{\mathrm{sh}}$ during transitional months for longer periods. Additionally, the need for the input of solar energy in colder months decreases due to the trend of increasing temperatures. The behaviour of $\mathrm{C}_{\mathrm{z}}$ range for Paris is slightly different than the one for Moscow and Berlin, because a drop in $\mathrm{C}_{\mathrm{z}}$ at the 90th percentile is projected for the year 2060, when a substantial increase in $\mathrm{V}$ value occurs due to high temperatures after the $\mathrm{CO}_{2}$ emissions around 2050 have reached peak according to RCP4.5. Thereupon, the $\mathrm{C}_{\mathrm{z}}$ in Paris at the 90th percentile starts to descend until 2090 and after. However, the $C_{z}$ values at 10th percentile for all the three locations, Berlin, Moscow and Paris, follow the projected increasing trend. Ljubljana's climate is temperate, similar as in Berlin or Paris. Therefore, the projected trends of $\mathrm{C}_{\mathrm{z}}$ in Ljubljana would be, for example, expected to behave like in the case of Berlin - increasing values of $\mathrm{C}_{\mathrm{z}}$ for both the 10th and 90 th percentiles. Instead, due to higher relative humidity and average temperatures, the need for overheating prevention (i.e. $\mathrm{V}$ value) in Ljubljana at the 90th percentile is projected to increase by more than $10 \mathrm{pp}$ until 2090, reaching $8 \%$ in 2060. In the event that this happens, a negative swing of $\mathrm{C}_{\mathrm{z}}$ for the 90 th percentile is estimated after 2060 (see Fig. 2), which was a surprising result. However, in Ljubljana, the behaviour of $\mathrm{C}_{\mathrm{z}}$ at 10th percentile is still similar to that in Paris, with a constant increment and a stabilization at the end of the century. Further in, it should be added that Ljubljana, due to its proximity to the Adriatic Sea, is characterized by substantial mixing of influences between the Mediterranean and temperate climates.

The projected temperature increase in Madrid will cause only a moderate increase in $\mathrm{C}_{\mathrm{z}}$ (for both the 10th and 90th percentiles), because the major intensification will be in the $\mathrm{V}$ value, which negates the effect of change in $\mathrm{C}_{\mathrm{sn}}$ and $\mathrm{C}_{\mathrm{sh}}$. In general, comparable environmental temperatures of Rome and Madrid could be expected to result in similar $\mathrm{C}_{\mathrm{z}}$ value, but for 


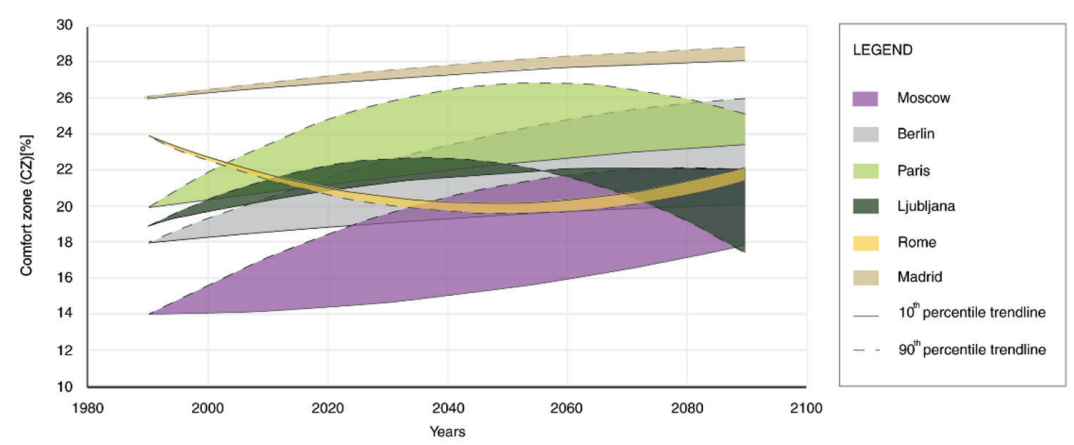

Figure 2: Plots showing $\mathrm{C}_{\mathrm{z}}$ of the analysed locations between 10th and 90th percentile.

Rome a substantial drop in $\mathrm{C}_{\mathrm{z}}$ is projected until the 2050 (Fig. 2). This happens because the climate of Rome is characterized by high relative humidity, higher than is typical for the hotarid climate of Madrid. This means that the achievement of comfort $\left(\mathrm{C}_{\mathrm{z}}\right)$ is conditioned by the relative humidity. After 2050 , the $\mathrm{C}_{\mathrm{z}}$ value in Rome is projected to increase due to the stagnation of the $\mathrm{V}$ value and reduction in $\mathrm{R}$. In Madrid and Rome, the difference between the 90th and 10th percentiles remains relatively constant, because the borders of comfort zone (i.e. 21 to $27^{\circ} \mathrm{C}$ ) do not enclose the interval of projected temperatures for the 90th and 10th percentiles. It could be assumed that a moderate increase of $\mathrm{C}_{\mathrm{z}}$ would be typical for warm and dry climates (e.g. Madrid). However, a decrease of comfort zone duration can be associated to higher humidity levels (e.g. Rome).

Based on the results for the projected $\mathrm{C}_{\mathrm{z}}$ range at the analysed locations we can conclude that according to the RCP4.5 climate change scenario in the future changes of bioclimatic potential will occur. Under projected circumstances, warmer climate conditions are expected, which will affect the amount of comfort. Increasing temperatures are projected to have a positive impact in colder and in dry temperate climates, where the increase in temperature will cause the rise of $\mathrm{C}_{\mathrm{sh}}$ and a minor decrease in $\mathrm{C}_{\mathrm{sn}}$. A minor increase of $\mathrm{C}_{\mathrm{z}}$ will be achieved in warm and dry climates. Considering the amount of the achieved $\mathrm{C}_{\mathrm{z}}$, high relative humidity has a negative impact in all climate types. A special case is the location of Ljubljana where up to 2060, projected bioclimatic potential is in line with the results of Berlin, Moscow and Paris. However, after 2060 a reversal of $C_{z}$ value is seen at the 90th percentile (the largest projected warming), testifying of possible change of climate type from $\mathrm{Cfb}$ to $\mathrm{Cfa}$. Something similar could also be said for the location of Paris, however in a less pronounced way. This conclusion is in line with the findings reported by Rubel and Kottek [21].

\subsection{Implications of projected changes in bioclimatic potential on the design of buildings}

Beside the projected changes in comfort zone $\left(\mathrm{C}_{\mathrm{z}}\right)$ range, presented in section 3.1, we were particularity interested in other results about bioclimatic potential at the analysed locations. Thus, future projected trends of the R (i.e. solar energy is desired but the amount available may be insufficient), H (i.e. only conventional heating is possible) and V (i.e. passive measures for overheating prevention are necessary) values were analysed in order to evaluate the trends in the importance of specific passive building design strategies. 

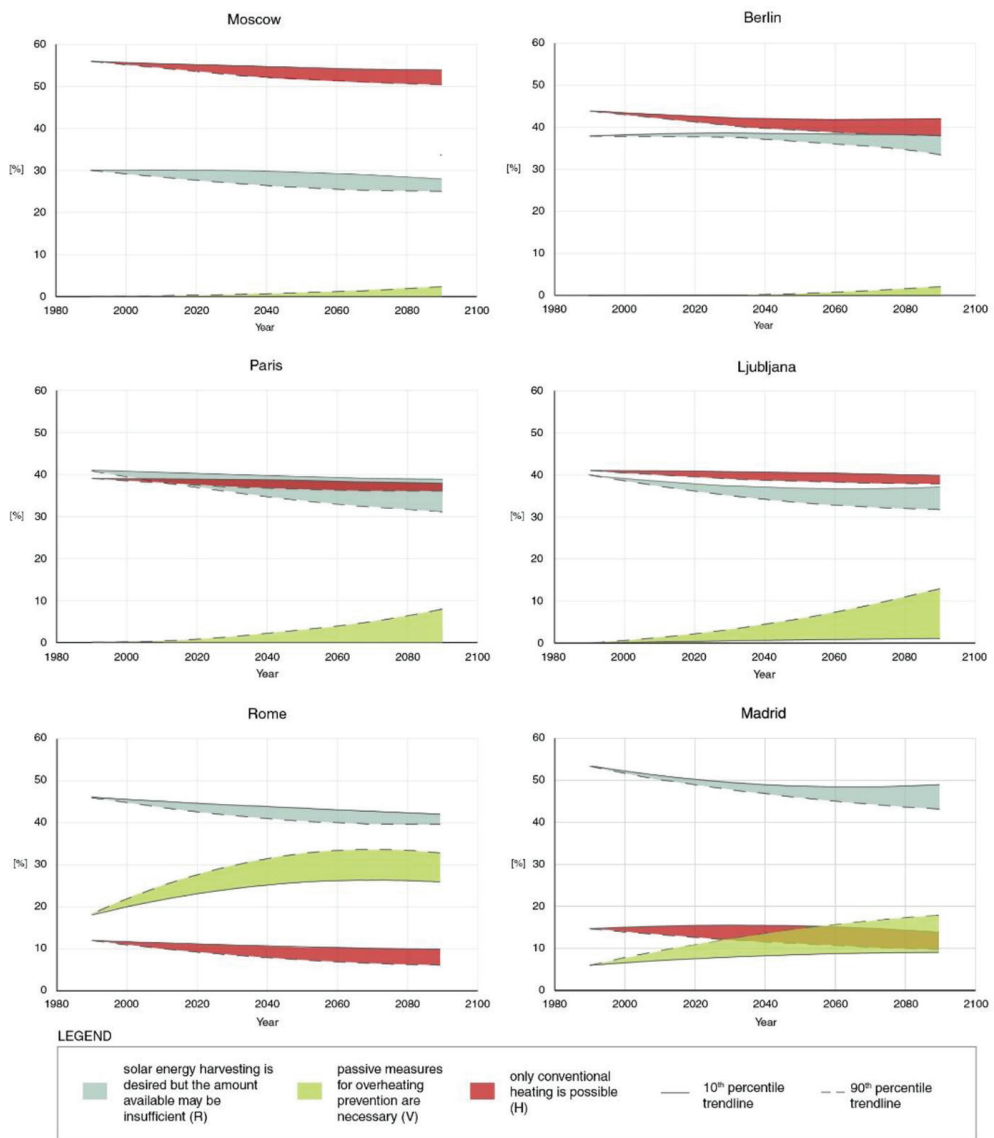

Figure 3: Future projected trends of the R, $\mathrm{H}$ and $\mathrm{V}$ values at different locations.

Observing Fig. 3 it can be seen that the analysed locations are practically congregated into three groups according to the bioclimatic potential. Moscow is the one with a particularly high value of $\mathrm{H}$, not falling below $50 \%$, a relatively low $\mathrm{R}$ value not exceeding $30 \%$ and an almost non-existent $\mathrm{V}$ value. The second group consists of Berlin, Paris and Ljubljana with a relatively high $\mathrm{H}$ value (around 40\%), however lower if compared to Moscow. For these locations, it is characteristic that the value of $\mathrm{H}$ and $\mathrm{R}$ are similar in magnitude (between $30 \%$ and $40 \%$ ). For Berlin, Paris and Ljubljana the V values vary on the case by case basis, where Ljubljana exhibits relatively high values at the end of 21 st century, particularly for the 90th percentile. The latter further testifies about the possible shift of climate characteristics for the location of Ljubljana mentioned in the previous section. The third group are the warmer locations of Madrid and Rome, where the $\mathrm{H}$ value is below $15 \%, \mathrm{~V}$ is relatively high and the $\mathrm{R}$ value is the highest (above 40\%).

In the light of climate change adaptation, the state of future bioclimatic potential should be observed in order to identify the dominant (i.e. primary) as well as the auxiliary passive building design strategies. By incorporating these strategies into buildings today, we enable the adaptation to projected climate change effects. However, such strategies will also have mitigation effects due to higher efficiency of buildings during their life cycle. As we already 
learnt by the results presented in Table 2, the Sh (i.e. shading needed) value will increase most in Berlin, Paris and Ljubljana, which is an important factor, since traditionally, buildings at these three locations, as well as in Moscow, are not designed according to overheating prevention criteria. The phenomenon is especially pronounced in Paris and Ljubljana, where air temperatures are expected to rise substantially and are mirrored in the trend of rising $\mathrm{V}$ value. Here, in addition to shading, also passive strategies for overheating prevention, such as intensive natural ventilation and high thermal mass, will be beneficial in order to maintain indoor thermal comfort. For example, until the end of the 21 st century the $\mathrm{V}$ value is expected to increase by $0-8$ pp and $1-13$ pp in Paris and Ljubljana, respectively. The results showed that among these three locations the highest $\Delta \mathrm{V}=13 \mathrm{pp}$ may appear in Ljubljana, where also the difference between the calculated 90th and 10th percentiles is the highest. The described situation can represent a substantial challenge for the design of buildings at locations such as Ljubljana and Paris, but to a lesser degree also in Berlin and Moscow. Shading of building envelope will become substantially more important for these locations and should be integrated in buildings, otherwise the duration of naturally (passively) achieved comfort $\left(\mathrm{C}_{\mathrm{z}}\right)$ will decrease. In addition, the retrofitting of existing buildings should be conducted in line with these findings. Ignoring this observation may result in lower indoor thermal comfort and concurrent increase in the use of mechanical cooling systems and consequential increase in electricity use. As a result, the building sector would even further diverge form the trajectory leading to sustainable future, because higher carbon footprint of electricity production would further increase $\mathrm{CO}_{2}$ emissions [7, 22].

Although in Madrid and Rome the Sh value is also projected to increase (Table 2), this effect of climate change is not as crucial as for the previously discussed locations, because the majority of buildings in hot-arid and Mediterranean climate are already designed according to overheating prevention demands. However, the expected change of bioclimatic potential at these two locations shows a rising importance of incorporating further overheating prevention strategies, i.e. the V value (Fig. 3). In both cases, Madrid and Rome, there may be a higher need for intensive natural ventilation, larger building mass and in the case of Madrid also for the direct or indirect evaporative cooling. In Madrid, this is expected to be effective for approximately $50 \%$ of the time during summer months. In Rome, the evaporative cooling would not be as efficient due to high relative humidity. For the same reason, in Rome the absolute $\mathrm{V}$ values in 2090 (26-33\%) and the $\Delta \mathrm{V}(8-15 \mathrm{pp})$ are much higher than in Madrid ( $\mathrm{V}=9-18 \%, \Delta \mathrm{V}=3-12 \mathrm{pp}$ ), mainly because during cooling season thermal comfort is harder to achieve only by passive building design measures at higher air humidity levels [23]. Observing Fig. 3, for Madrid and Rome an evident decrease of the $\mathrm{H}$ value can be expected. The latter is projected to drop by $2-5 \mathrm{pp}$ and $2-6 \mathrm{pp}$, respectively, which means that the part of the year when only conventional heating is possible, is decreasing. This should reflect in lower energy use for heating. Similarly, an evident reduction of R value can be recognized as well (Fig. 3). The phenomenon of diminishing $\mathrm{H}$ and $\mathrm{R}$ values is also obvious at other four locations. Nevertheless, in Moscow, Berlin, Paris and Ljubljana, passive solar heating still remains the primary passive building design strategy. In particular, at all the four locations the duration when only conventional heating is possible (the $\mathrm{H}$ value) stagnates around $40 \%$ of the year.

The presented results of comfort zone change as well as the change in the related bioclimatic potential for passive heating and cooling can have substantial impact on the quality of indoor environment and the energy performance of buildings. Although results presented above project an increase of $\mathrm{C}_{\mathrm{z}}$, meaning that longer duration of indoor comfort is achieved 
by passive strategies, it has to be stressed that these values are attained under the presumption of effective shading (i.e. $\mathrm{C}_{\mathrm{sh}}$ ) and effective passive heating (i.e. $\mathrm{C}_{\mathrm{sn}}$ ). Without adequate implementation of passive strategies for overheating prevention, it can be expected that future energy use in buildings will increase due to the use of mechanical cooling, while this increase will not be offset by a projected decrease in heating demand $[8,9]$. In such scenario, the building energy use would further intensify the climate change effects through a feedback loop, increasing radiative forcing in the atmosphere [14]. These findings are of particular importance for locations traditionally not affected by solar irradiation induced overheating in buildings, namely locations having low $\mathrm{V}$ values at present.

\subsection{Eco-economic implications of projected bioclimatic shifts}

The above-described implications of projected climate change may have an extensive influence on building energy performance at some of the locations. The most challenging impact will be expressed in the increase of cooling need at locations with temperate climate, such as Ljubljana. In the previously conducted study by Pajek and Košir [9], we demonstrated that in the temperate climate of Slovenia a substantial increase in cooling energy use (i.e. $\mathrm{Q}_{\mathrm{NC}}$ ) due to climate change is projected. Thus, buildings at these locations will need extensive application of shading in order to limit the increase in $\mathrm{Q}_{\mathrm{NC}}$.

The most common way to shade buildings is by implementing external mechanical shades (e.g. shutters) on the sun-exposed windows. Therefore, we decided to analyse the ecological and economic impact of installing shading in the case of two thermally well insulated buildings situated in Ljubljana; one bioclimatic and one conventional building of equal floor area $\left(\mathrm{A}_{\mathrm{u}}=162 \mathrm{~m}^{2}\right)$ but different envelope configurations (Table 3). Data for current and projected future energy performance of the two buildings were taken from the above-mentioned study. For the ecological evaluation of the installed shading devices the annual average reduction in electrical energy for cooling $\left(\Delta \mathrm{Q}_{\mathrm{CEL}}\right.$ in $\mathrm{kWh} /$ year $)$ and $\mathrm{CO}_{2}\left(\Delta \mathrm{CO}_{2}\right.$ in $\mathrm{kg} /$ year $)$ emissions were observed with respect to the shaded and unshaded state of the buildings. For the economic evaluation we used the related static investment payback period ( $\mathrm{P}_{\mathrm{t}}$ in years) and the

Table 3: Eco-economic implications of projected climate change for the period between 2019 and 2049 on a case of two residential buildings situated in Ljubljana.

\begin{tabular}{llllll}
\hline Building description & $\begin{array}{l}\text { Investment } \\
(€)\end{array}$ & $\begin{array}{l}\Delta \mathrm{Q}_{\mathrm{CEL}} \\
(\mathrm{kWh} / \text { year })\end{array}$ & $\begin{array}{l}\Delta \mathrm{CO}_{2}(\mathrm{~kg} / \\
\text { year })\end{array}$ & $\mathrm{P}_{\mathrm{t}}$ (years) & IRR (\%) \\
\hline Bioclimatic building & $5,000.00$ & $2,249.87$ & $1,192.43$ & 17.01 & 4.70 \\
& & & & & \\
Conventional building & $4,200.00$ & $1,087.67$ & 576.46 & 27.25 & 1.00 \\
\hline
\end{tabular}


internal rate of return (IRR in \%). The buildings were presumed to be cooled by an airconditioner with Energy Efficiency Ratio (EER) of 3.5. The price of electrical energy was taken as $0.125 € / \mathrm{kWh}$ and an annual increase in energy price was set to $1 \%$, both according to OpenExp report [24]. The starting investment into solar-radiation-intensity-based automatically controlled external shading was obtained from the local manufacturer and differs for each building due to different area of windows $\left(39.7 \mathrm{~m}^{2}\right.$ for bioclimatic and $21.6 \mathrm{~m}^{2}$ for conventional building). The observed period of buildings' performance was 30 years (2019 to 2049). Table 3 presents the results of the conducted analysis. The results show that both ecological and economic impacts are more favourable in the case of bioclimatic building. This is primarily because the bioclimatic building was optimised for solar energy harvesting during wintertime, which makes it more susceptible to overheating. However, the investment in shadings is still acceptable in both cases.

\section{CONCLUSIONS}

The main implications and conclusions of the presented projected impact of the IPCC's RCP4.5 climate change scenario on the bioclimatic potential of buildings in selected six locations can be summed up as follows:

- The range (i.e. length) of comfort zone achieved by passive means in buildings is projected to increase for all the locations except for Rome.

- The results of projected bioclimatic potential at the 90th percentile for Ljubljana show a shift in climate type from Cfb to Cfa. A similar trend is also evident for Paris.

- The relative importance of overheating prevention measures will predominantly increase at locations where buildings are traditionally optimised for heating season (i.e. have large surfaces of glazing for passive heating), like Ljubljana and Paris and to a smaller degree Berlin and Moscow.

- The shift in bioclimatic potential in northern and central Europe poses a challenge in building energy use, which may result in additional $\mathrm{CO}_{2}$ emissions.

- The application of shading as part of one-step energy renovation in temperate climates has positive ecological impacts and has acceptable economic viability.

\section{ACKNOWLEDGEMENTS}

The authors acknowledge the financial support from the Slovenian Research Agency (research core funding No. P2 - 0158).

\section{REFERENCES}

[1] Bai, X., Dawson, R.J., Ürge-Vorsatz, D., Delgado, G.C., Salisu Barau, A., Dhakal, S., Dodman, D., Leonardsen, L., Masson-Delmotte, V., Roberts, D.C. \& Schultz, S., Six research priorities for cities and climate change. Nature, 555(7694), pp. 23-25, 2018. https://doi.org/10.1038/d41586-018-02409-z

[2] IPCC, Intergovernmental Panel on Climate Change, AR5 Report, 2014.

[3] Edenhofer, O., Pichs-Madruga, R., Sokona, Y., Minx, J.C., Farahani, E., Kadner, S., Seyboth, K., Adler, A., Baum, I., Brunner, S., Eickemeier, P., Kriemann, B., Savolainen, J., Schlömer, S., von Stechow, C. \& Zwickel, T., Climate Change 2014: Mitigation of Climate Change. Contribution of Working Group III to the Fifth Assessment Report of the Intergovernmental Panel on Climate Change, 2014.

[4] Pardo Martínez, C.I., Alfonso Piña, W.H. \& Moreno, S.F., Prevention, mitigation and adaptation to climate change from perspectives of urban population in an 
emerging economy. Journal of Cleaner Production, 178, pp. 314-24, 2018. https://doi. org/10.1016/j.jclepro.2017.12.246

[5] EPBD-R 2010/31/EU, Energy performance of buildings (recast), 2010.

[6] Directive 2009/125/EC, Establishing a framework for the setting of ecodesign requirements for energy-related products (recast), 2009.

[7] Li, D.H.W., Yang, L. \& Lam, J.C., Impact of climate change on energy use in the built environment in different climate zones - A review. Energy, 42(1), pp. 103-112, 2012. https://doi.org/10.1016/j.energy.2012.03.044

[8] van Hooff, T., Blocken, B., Timmermans, H.J.P. \& Hensen, J.L.M., Analysis of the predicted effect of passive climate adaptation measures on energy demand for cooling and heating in a residential building. Energy, 94, pp. 811-820, 2016. https://doi. org/10.1016/j.energy.2015.11.036

[9] Pajek, L. \& Košir, M., Implications of present and upcoming changes in bioclimatic potential for energy performance of residential buildings. Building and Environment, 127, pp. 157-172, 2018. https://doi.org/10.1016/j.buildenv.2017.10.040

[10] Olgyay, V., Design with climate, Princeton University Press: New Jersey, USA, 1963.

[11] Manzano-Agugliaro, F., Montoya, F.G., Sabio-Ortega, A. \& García-Cruz, A., Review of bioclimatic architecture strategies for achieving thermal comfort. Renewable and Sustainable Energy Reviews, 49, pp. 736-755, 2015. https://doi.org/10.1016/j. rser.2015.04.095

[12] Košir, M. \& Pajek, L., BcChart v1.0. University of Ljubljana, Faculty of Civil and Geodetic Engineering, 2016.

[13] Pajek, L. \& Košir, M., Can building energy performance be predicted by a bioclimatic potential analysis? Case study of the Alpine-Adriatic region. Energy Build, 139, pp. 160-173, 2017. https://doi.org/10.1016/j.enbuild.2017.01.035

[14] Houghton, J.T., Global Warming: The Complete Briefing, 5th edn., Cambridge University Press: Cambridge, 2015.

[15] Moss, R. (ed), Intergovernmental panel on climate change. Towards New Scenarios for Analysis of Emissions, Climate Change, Impacts, and Response Strategies: IPCC Expert Meeting report 19-21 September, 2007, Intergovernmental Panel on Climate Change: Noordwijkerhout, The Netherlands and Geneva, Switzerland, 2008.

[16] Thomson, A.M., Calvin, K.V., Smith, S.J., Kyle, G.P., Volke, A., Patel, P., DelgadoArias, S., Bond-Lamberty, B., Wise, M.A., Clarke, L.E. \& Edmonds, J.A., RCP4.5: a pathway for stabilization of radiative forcing by 2100. Climatic Change, 109(1-2), pp. 77-94, 2011. https://doi.org/10.1007/s10584-011-0151-4

[17] Köppen-Geiger. World map of the Köppen-Geiger climate classification updated - The underlying data (High resolution map and data), 2017. http://koeppen-geiger.vu-wien. ac.at/present.htm (accessed on 5 April, 2018).

[18] Google. Google Earth 2018. https://earth.google.com/web/ (accessed on 5 April, 2018).

[19] EnergyPlus. Weather Data 2018. http://energyplus.net/weather (accessed on 2 March, 2018).

[20] Arup North America Ltd (Arup), Argos Analytics LLC, and Slate Policy and Design. WeatherShift 2018. http://weather-shift.com/ (accessed on 5 April, 2018).

[21] Rubel, F. \& Kottek, M., Observed and projected climate shifts 1901-2100 depicted by world maps of the Köppen-Geiger climate classification. Meteorologische Zeitschrift, 19(2), pp. 135-141, 2010. https://doi.org/10.1127/0941-2948/2010/0430 
[22] Yang, L., Yan, H. \& Lam, J.C., Thermal comfort and building energy consumption implications - a review. Applied Energy, 115, pp. 164-173, 2014. https://doi.org/10.1016/j. apenergy.2013.10.062

[23] Naveen Kishore, K. \& Rekha, J., A bioclimatic approach to develop spatial zoning maps for comfort, passive heating and cooling strategies within a composite zone of India. Building and Environment, 128, pp. 190-215, 2018. https://doi.org/10.1016/j. buildenv.2017.11.029

[24] OpenExp. Deep Energy Renovation: Trapped in Overestimated Costs and Staged Approach, Paris, 2018. 